\title{
STRUCTURE OF THE FEMALE REPRODUCTIVE ORGAN OF PIG ASCARIS*
}

\author{
KEIICHI ISHII AND TOSHIO YANAGISAWA \\ The National Institute of Health, Tokyo \\ (Received: October 2nd, 1953)
}

In the series of the studies on the physiology of ascaris eggs, here the cytoand histochemical observations of their oögenesis and egg-shell formation were carried out. On the histological as well as gross structures of the female reproductive organ of ascaris, only few works were available (Ida, 1930; Suzuki, 1938; Murata, 1950; Izumi, 1952; Yamaguchi, 1952).**

The object of this paper is to clear up the detailed structure of the whole female reproductive organ of pig ascaris.

\section{MATERIAL AND Methods}

Adult fresh female Ascaris suilla of about $30 \mathrm{~cm}$ long were collected from the pig intestines at Shibaura Butchery, Tokyo. The specimens of reproductive organs from these living worms were fixed in $80 \%$ ethanol, $50 \%$ formol, $10 \%$ buffered formol ( $\mathrm{pH}$ 7.0), Schaudinn's, Rossman's, Kahle's (acid free), Champy's and Regaud's fixatives, then embedded in paraffin through isopropyl alcohl and terpineol-benzol or dioxan. Usually 4 and $6 \mu$ thick sections were stained by Mann's, Cason's (1950) and Q-stain, occasionally by alum hematoxylin modified by Lillie (1942), Rafalko's Feulgen reaction, methyl green-pyronin, van Gieson's, Giemsa, HCl-Giemsa and toluidin blue were also employed. Among these stains Azure B type Giemsa stain after the treatment by $\mathrm{HCl}$ was proved excellent not only for demonstrating basophilia but also for the differential staining of the egg shell. Cason's and Q-stain were also reliable for the general observation of these tissues after fixing by sublimate or chromium fixatives. Stained section were mounted in caedax (Bayer) through the series of acetonexylol.

In the following descriptions the female reproductive organ or pig ascaris was divided into following five parts: A (initial ovary), B (ovary), C (oviduct and seminal receptacle), $\mathrm{D}$ (uterus) and $\mathrm{E}$ (vagina). The fixatives and stains used in this work were abbreviated as follows: Formol (F), Ethanol (E), Schaudinn's (Sch), Regaud's (RG), Mann's (MN), Cason's (Cas), Q-stain (Q), Giemsa (G) and Toluidin blue (TB).

* Biological studies on Ascaris eggs 6.

* For further references on this problem, see Yamaguchi (1952). 


\section{RESULTS}

\section{A-1 (pl. 1-1)}

This is the initial part of the ovary. This and the next part (A-2) are identical with so called "primitive ovary". About half length of the ovary belonged to this part. The diameter of ovary in this part was measured about 60 to $80 \mu$. The flat epithelial cells surrounding the mass of the round oögonia were found as a single layer, and attached on the basal membrane by their basal part. These cells varied in size and arranged in the periphery of the central mass of oögonia. Most of them showed vacuolation in their reticulated cytoplasm. No specific cytoplasmic granules were found in them. The elliptical nucleus was found in the central part of the cell. It consisted of poor chromatin granules, unstained enchylema and one to five rounded nucleoli. On the basal membrane forming the outer layer of ovary no remarkable structure could be demonstrated but its inner and outer margin were stained more intensely by RG-MN, RG-G and Sch-MN. No axis was yet observed. The intercellular substance was more indistinct here than that in the next part (A-2). This substance was considered to differentiate into the axis later. Oögonia in this part were round or ellipsoidal in shape and situated closely together. No descriptions has been available on this initial part of the ovary.

\section{A-2 (pl. 1-2, 3)}

This is the second lower part of the ovary and was about $5-8 \mathrm{~cm}$ long. The diameter of ovary in this part was measured 70 to $90 \mu$. Epithelial cells resembled those in A-1 in its structure and affinity for stains used, but differed from those in A-1 on arrangement of cells. Here they were likely to situate separately one another. The nuclear membrane and peripheral chromatin of the epithelial cell were found stained uniformly but feebly by TB. The general structure of nucleolus was similar to that in A-1, and especially demonstrated clearly magenta in colour by $\mathrm{MN}$ or $\mathrm{Q}$.

Basal membrane was the same as in A-1, but intercellular substance located between the inner side of basal membrane and epithelial cells were found stained dark blue by F-TB, and slightly by Sch-MN. But by other stainings any definite structure could be hardly recognized in it. The axis of ovary was considered to be formed from the intercellular substance which filled the space between each oögonium (text fig. 1-1, pl. 1-2). From this part, intercellular substance in the central and several peripheral areas of ovary was found increased quantitatively, gradually conglomating itself into several masses. Peripheral masses of intercellular substance were found connected with the central only by each narrow fibrous branch to make a radical axis lamified irregularly (text fig. 1). The distal parts of peripheral axis were branched finely and transformed into the intercellular substance between the oögonia. At the successive part of ovary peripheral axial substance increased in their shape in accordance with the decreasement of the diameter of central axis, gradually forming "bilobate radical 

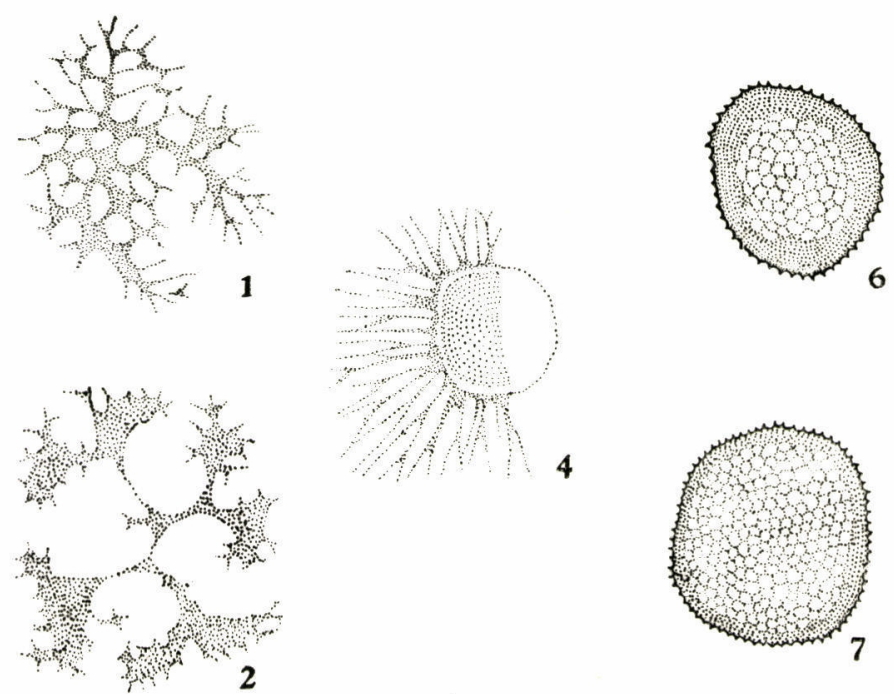

4
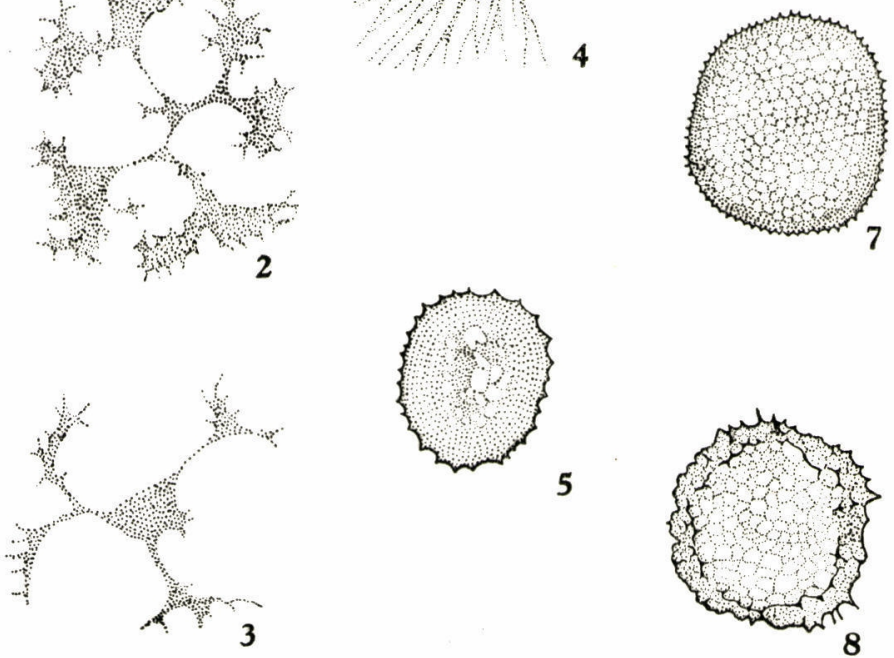

5

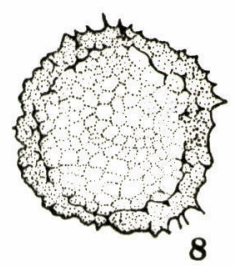

Fig. 1. The differentiation of axis in ovary of pig ascaris.

axis". The latter was found consisted of a narrow central axis and 3 or 4 "bilobes" of peripheral axial substance (fig. 1-2, pl. 1-3). These axis was stained with RG-Q or RG-Cas (brown), RG-MN (blue) and RG-G (fine purple) and showed fibrous or indifferentiated structures. Sch-G (purple) was an excellent staining method for the differentiation of the axis from oögonia. At this part oögonia increased their cytoplasm and the axis between the oögonia groups to which the germ cells attached became clearer (fig. 1-2, pl. 1-3).

At the lower part of A-2, larger "bilobe" peripheral axis became decreased in their size and finally became undemonstrated. On the contrary, central axis increased in their size gradually and formed single cylindrical axis to which oöcytes attached radially. The latter increased their size here (text fig. 1-3, 4). In this part the nucleus of oöcytes in growth period did not yet arranged on a same line forming a circle around the central axis (pl. 1-4). 


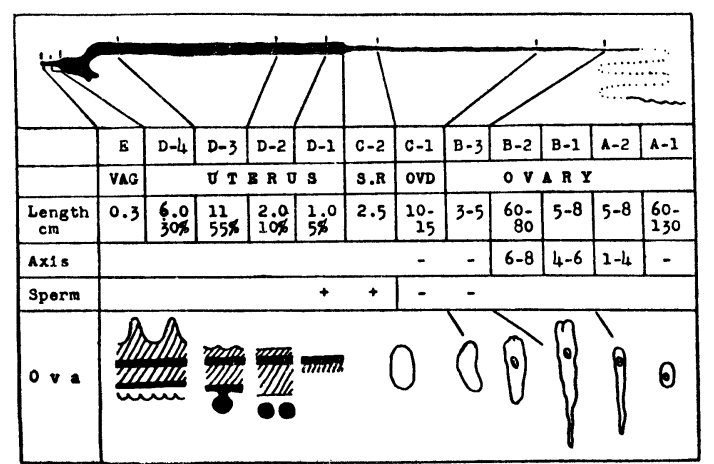

Fig. 2. The schema of twelve parts of the female reproductive organ of pig ascaris.

\section{B-1 (pl. 1-4, 5, 6)}

This part is 5 to $8 \mathrm{~cm}$ long, and the diameter of ovary showed about 90 to $200 \mu$. At the upper part of B-1, the general feature of epithelial cells were about the same as those in A-2, while at the lower part appeared spindle epithelial cells showed circular or semicircular form in sections. Most of the cells showed in their cytoplasm several small vacuoles stained heavily. Each epithelial cells attached to the basal membrane with their one or three cytoplasmic processings protruding on the basal part of their cytoplasm. Each processing showed itself as a strong acidophilic rounded structure which was not so remarkable as those in the next part (B-2). Elliptical nucleus possessed one to six or more strong acidophilic nucleoli and feebly stained chromatin in it, and was localized in the central portion of the epithelial cell. The nucleus could be demonstrated only by $\mathrm{G}$ or Feulgen reaction (pl. 1-5). Definite intercellular substance was formed between each epithelial cell. The ovary showed smooth circular outline at the lower parts of B-1.

The basal membrane was the same as that in A-2. In cross sections, its inner layer stained red-purple whilst the outer one stained violet by F-TB, but it seems to be optifact, because the affinity of the former for stain was similar to that of intercellular substance and no red-purple reaction of the inner layer could be observed clearly with F-TB in the longitudinal sections. At the transitional part of A-type epithel to B-type one, a very large central axis was observed. It consisted of three parts; the feebly stained peripheral part attached to the growing oöcytes, the more intensely stained second part and the coarse vesicular central part. At the part of ovary showing B-type structure the axis decreased in its diameter and was found circular in shape in its section. The boundary of the weak stained outer layer and oöcytes was indefinite. The central parts of the axis was found vesicular and was surrounded by the intermediate layer. The ground substance of the later was compact (text fig. 1-4, 5, pl. 1-5, 6). 
The position of oöcytes in maturating stage were not always correspond with that of the reproductive tube taking the structure of overy and such aspects were found somewhat different in each worms. However, at the transitional part of A to B-type the nuclei of oöcytes including one to three small nucleoli were not yet situated generally in their distal portion but situated irregularly between its proximal and distal parts. At the lower part of ovary, nuclei of oöcytes including large nucleoli were located in the distal part of cytoplasm in which neither microsomes stained red by MN nor cytoplasmic granules to form inner shell-layer (Yanagisawa and Ishii, in press) were found yet.

B-2 (pl. 1-7, 8, 9, pl. 2-10)

This is the longest part ( 60 to $80 \mathrm{~cm}$ long) of the ovary, and was measured about one-third length of the whole. Cross section was measured about 200 to $380 \mu$ in its diameter. The general structure of epithelial cells were the same as that in former part, but their processings attaching on the basal membrane were found more conspicuous and less in their number than that in B-1. A fibrillae laying longitudinally in each processing were demonstrated finely with congo red (intense red), F-MN (dark red), E-Q (magenta), RG-Q (red-purple or pink) and van Gieson's (Yellow) (pl. 1-9). Their various staining affinity suggested that they would be "tonofibrillae". The shape of epithelial cells in cross section were varied according to the number and position of their processings, measurring 6 to $12 \mu$ in breadth. In the cytoplasm no particular structures could be demonstrated. After fixing in E, however, a gibbous structure stained red with Cas appeared in proximal portion of cytoplasm stained intense purple. But these structure were supposed one of the artifact produced by exposing it under the solitary and unbalanced penetrating flow of single alcohol used as fixative. Because such an artifact was usually observed only after simple alcohol fixation and epithelial cells thus fixed transformed their shape along the penetrating direction of alcohol. - The structure of epithelial nuclei resembled those in B-1.

Intercellular substance between each epithelial cell stained more intensely than those in B-1 (pl. 1-9). Basal membrane was as same as in B-1. The axis decreased in its diameter gradually and measured for about 20 to $60 \mu$. It was divided into the rough reticular central part and the dense marginal part stained more intenselly than the central one (fig. 1-6, 7, pl. 1-7). The boundary of these two parts was definite. At the terminal part of ovary, the axis was measured for 20 to $26 \mu$ in diameter, and showed alveolar structure in its central and peripheral parts (fig. 1-8, pl. 1-8, 9). The axis finally became rough alveolar in structure which showed no differentiation into central or peripheral parts, then gradually disappeared decreasing its diameter (pl. 2-10).

Cytoplasmic granules began to appear in the proximal cytoplasm at the upper part of B-2, gradually situating evenly in their cytoplasm at the lower part of B-2 (pl. 1-9). The stage of oöcytes in this part corresponded with its last growth period. 
B-3 (pl. 2-11, 12)

This was about $5 \mathrm{~cm}$ long and measured about 300 to $400 \mu$ in its diameter. No irregular outline was shown in the section. The processings of epithelial cells were very few in number and usually no processing was observed, therefore rough cytoplasm showed small vaculoar and fibrous structures, occasionally the gibbous mass appeared in the cytoplasm not only after treatment of alcohol but by general fixatives. Nucleus including two to five nucleoli was more distinct than that in B-2, and intercellular substance stained feebly red-purple by TB as in B-2. On the outer side of the basal membrane, usually primitive muscle layer stained red-purple by F-TB, but these elements of the muscle layer were not differentiated yet and demonstrated clearly only by F-TB. The axis disappeared at this part (pl. 2-11), and at the lower ovary elongated ellipsoidal oöcytes were found free from the epithelial cells (pl. 2-12).

\section{C-1 (pl. 2-13, 14)}

This is the oviduct following to $\mathrm{B}-3$, and was measured about 250 to $350 \mu$ in diameter and 10 to $15 \mathrm{~cm}$ in length. Here the boundary between each folded or gibbous epithelial cell was not demonstrated by any silver impregnation (e.g. Nie's mod. of Bodian's protargol method, 1950; Del Rio-Hortega's method). Coarse cytoplasm included many vacuoles in its folded portion and in some cases in the extremity of the bulgy portion numerous minute eosinophilic microsomes was found by F-MN. Elliptical polynucleolar nucleus near the base of the cell was poor in chromatin, stained feebly and occasionally could not be demonstrated. In the basal part of the cytoplasm two or three fibrilla-like structures were found distributed irregularly as described by Yamaguchi (1952).

In the lower part of $\mathrm{C}-1$, the intermediate type of $\mathrm{C}-1$ and $\mathrm{C}-2$ was observed (pl. 2-14). Cytoplasm of these epithelial cells were fixed in reticular or vacuolated structure and eosinophilic granules were not demonstrated in them. These epithelial cells were elongated lozenge in shape and two nuclei situated in the extremities of each cell were observed in the longitudinal sections. Usually a large nucleolus situated in the round nucleus stained obviously, sometimes large nucleolus and two or three smaller ones appeared in them but generally were fewer in number than those in upper part. The basal membrane was thick and stained evenly. From this part, the cortical muscle layer appeared in the outer part of the basal membrane. At the upper part of C-1, cortical muscle layer was composed of the layered muscle cells in which myofibrillae were not differentiated yet, while at the lower part of oyiduct myofibrillae were formed and situated horizontally in the cytoplasm near the basal membrane. The thick intercellular substance protected the muscle cells. At the transitional part between $\mathrm{C}-1$ and $\mathrm{C}-2$, the muscle cells situated rather obliquely and each cell became fasciolate. The oöcytes at the lower part of C-1 were already grown up. No spermatozoa were found in the cavity. 
C-2 (pl. 2-15)

This is the seminal receptacle and was about 1 to $3.5 \mathrm{~cm}$ long just above the uterus and about 400 to $600 \mu$ in diameter. The elongated extremity of epithelial cell protruded into the inner cavity and occasionally protruded cytoplasm was very narrow and linear, while the basal part of the cell near the basal membrane was thick. No remarkable outline between cells was demonstrated. Cytoplasm showed rather fibrous, and the polynucleolar nucleus situated near the basal membrane and stained intensely. The cortical muscle layer outside of the definite basal membrane was composed of the elongated spindle muscle cells situating horizontally or obliquely, and the cells were fasciolate together and among them more developed muscle fibers were formed near the basal membrane. The thick intercellular substance covered the muscle cells above mentioned (pl. 2-15). The nucleus of these muscle cells were ellipsoidal in shape and polynucleolar. Here only the holds of the epithelial cells were surrounded by numerous spermatozoa. Ovium was fertilized at this part or at the next D-1, but no distinguishable egg-shells were yet formed.

D-1 (pl. 2-16)

This is the initial one-fifth part of the uterus. The epithel was formed from only one layer of epithelial cells. They connected with each other on the basal parts and the boundary of each cell was indistinct. In the longitudinal section each cell was lozenge shaped possessing two nucleoli in it. The cell was formed from three parts; (1) basal part, (2) intermediate part and (3) extreme bulgy part. The basal part was found fixed as fibrous structures and no differentiated granules were observed. The narrow intermediate part was compact and therefore stained more intense blue by F-MN and showed basophilic reactions. The inflated extreme part was formed from reddish central part and peripheral one. The latter part containing an amount of bluish minute granules were seen by the treatment of F-MN. The anterior half of the extreme bulgy part was shown occasionally free from the cell in the fixed section and in these cases both bluish granules and reddish hyaloplasm were contained in it. These facts indicated that the part freed from the cells should be the secretory substance. However these feature observed on the uterine epithelial cells were variable in section, for examples; in some cases both the peripheral cytoplasm and the large vacuoles involved several large granules formed in the peripheral cytoplasm were secreted together, and in other cases no granules were demonstrated in feebly stained cytoplasm. These different feature of secretion was considered either to suggest the existence of several types of the secretion of different cells or to indicate the different stages of the secreting rhythms of the same secretory cells. Generally the extreme and intermediate parts of cytoplasm contained cytoplasmic fibrillae (elgastoplasmic fibrillae) situating longitudinally. They were alike to "fibrous secretory cells", while in the peripheral cytoplasm contained no fibrillae and the boundary of two parts was distinct. Large round or elliptical nucleus situated 
in the basal part included dispersed or microgranular chromatin in it. The latter formed no chromatin mass or network in any fixed materials. The nucleoli varied in form and size. The basal membrane was robust and fine. The compasition of cortical layer resembled that in C-2. Eggs in this part of uterus already finished their fertilization and formed middle egg-shell layer and in most eggs cytoplasmic granules were found situated in the vicinity of the shell.

D-2 (pl. 2-17, 18)

This is $10 \%$ long of the whole uterus and measured about $1000 \mu$ in diameter. The Epithelial cell resembled those in D-1, the intermediate part of the cell was broader and shorter, and the extreme part was longer and gibbous than those in D-1. Throughout the uterus the same epithelial cell was found fixed in different form by the various fixatives used. For examples, the epithelial cell at this part was demonstrated rectangular by the fixation of $F$ (pl. 2-18), but the intermadiate part extremely narrow by Sch fixation because its tip part was inflated and gibbous (pl. 2-17). The peripheral part of the extremity consisted of hyaloplasm as shown in D-1, but differed from D-1, few granules were found in them but the large secretory granules described at D-1 could not be demonstrated. Other parts of the cytoplasm were vesicular or fibrous. In some cells, a large vacuole (degenerating nucleus ?) containing weak acidophilic granules in their terminal parts was found in the center of the more inflated extremity of cells. But smooth acidophilic secretory substance stained red by $\mathrm{MN}$ as described in D-3 was not yet observed in them. The structure of nucleus was the same as that in former part. Sometimes numerous minute granules stained red were seen in the vicinity of the nucleus. Basal membrance and cortical muscle layer resembled in $\mathrm{D}-1$. The ova at this part were in the stage of middle shell formation, and some covered with smooth protein coat were found already appeared in the section. Localization of cytoplasmic granules was the same as in $\mathrm{D}-1$.

\section{D-3 (pl. 3-19, 20, 21)}

This is the longest part of the uterus $(50-55 \%)$ and measured about $1200 \mu$ in diameter. Epithelial cells showing typical structure of the secretory cell were more elongated than those in $\mathrm{D}-2$, and were fixed into the rectangular form possessing somewhat trancated terminal tip by $\mathrm{F}$-fixation, while into the cylindrical form with narrow middle part and gibbous terminal tip by Sch fixation. Rough cytoplasm was formed of typical elgastoplasmic fibrillae situated along the radical axis of the uterus. As the result of the increase of these secretory granules, hyaline peripheral part of their extremity including bluish granules stained by F-MN was inflated and finally formed double gibbous tips (pl. 3-19). In some cases terminal part of these double tips was inflated exceedingly. In these tips contained secretory substance stained reddish by F-MN. As a result of this the epithelial cells transformed its shape into elongated ones having double cells appearance. This cell consisted of four parts; (1) fibrous basal part, 
(2) narrow fibrous intermediate part, (3) vacuolated or hyaline peripheral part containing many granules and (4) gibbous terminal tip filled eosinophilic secretory substance (pl. 3-20). In some cases reddish granules appeared in the peripheral cytoplasm of its extreme part and in other cases reddish granules located in the vicinity of nucleus and in the basal part of the cell were observed after treating by F-MN. The appearance of these secretory granules and substances were thought to be related closely with the protein coat formation. The basal part of epithelial cells contained the elgastoplasmic fibrillae and one or two rows of the tonofibrillae. The latter became more robust as the cell was found in the lower part of the uterus. Two large elliptical nuclei localized in the transitional part of intermediate and basal part of epithelial cell was the same as those in D-2, and its longitudinal axis faced to the center of the cavity of uterus (pl. 3-20, 21).

Basal membrane and cortical layer were similar to those in D-2. The middle layer of the shell of some eggs were formed up already and the cytoplasmic granules were fading out. Smooth protein coat were formed up on every ova and frequently spines of coat were also seen.

D-4 (pl. 3-22, 23, 24, 25)

This is the terminal part of the uterus (30\% long of whole uterus). Small rectangular epithelial cells were poor in their ground substance and possessed thick protoplasmic membrane, and remarkable artifact occurred as fixative varied (pl. 3-22, 23, 24, 25). They usually possessed bluish granules in their peripheral cytoplasm and no reddish granules or secretory substance in the inflated part were demonstrated by F-MN. Fibrous structure of cytoplasm was found more in its extreme part and less in its intermediate and basal parts. From these observation, the activity of the secretion of this part was supposed poor than that of D-3. Vacuolated nucleus consisted of the irregular outline of thick nuclear membrane, dispersed chromatin, two to six or more nucleoli varied in size and non stained enchylema. Dispersed chromatin showed weak reaction of desoxyribonucleic acid by Feulgen's reaction and methyl green-pyronin. Non stained hyaline ring of the cytoplasm was found surrounding the nucleus by any fixatives used in this works (pl. 3-22, 24).

In the boundary of each cell, about two to ten eosinophilic granules appeared by F-MN, but their nature was not made clear. Both definite basal membrane and outer cortical muscle layer resembled those in D-3 but the elliptical nucleus of muscle cell including one to three nucleoli was larger and stained intensely.

At this part, spinal protein coat was produced perfectly while in unfertilized egg cytoplasmic granule fused together to form several large globules. Spermatozoa were concentrated in spaces between each epithelial cell.

Previous workers called only branched parts of the reproductive organ as uterus, but about half length of an unbranched part following to binary uterus showed also uterine structure as described here. This apparently indicates that 
not only branched part but also about a half length of an unbranched one should be called as uterus and only a last half part of the unbranched part should be regarded as vagina.

E. (pl. 3-26, 27)

The vagina measured about $0.3 \mathrm{~cm}$ long and 400 to $500 \mu$ in diameter. Generally speaking, the composition of the tissues was homologous to the terminal part of the male reproductive organ. Epithelial cells resembled as those of D-4, but their surface were covered with the thick layer of secretory substance stained uniformly. The vaginal cavity was therefore very narrow. Differed from uterus, several longitudinal muscle cells were situated partially between each epithelial cell. The Basal membrane was the same as in D-4, but was more indefinite. The outer muscle layer was formed of several layers consisted of thick protecting intercellular substance and numerous spindle muscle cells heaped up together. In the latter the large and heavy muscle fibers were observed. Other structure were similar to those in D-4.

The authors are indebted to Dr. Yoshitaka Komiya, Chief of the division, for his invaluable advice and encouragement.

\section{SUMMARY}

Histological observations of the female reproductive organ of pig ascaris were made and the following results were obtained:

1) The axis of the ovary was not observed in the upper part of the ovary. It appeared at its middle part as a differentiated structure originated from the intercellular substance among the oögonia. The upper part of the axis was radiated and lamified in section, however, after various changes of form lower part of it was proved to be typical cylinder in shape as shown in text figures.

2) The wall of the ovary consisted of a layer of the cells possessing a nucleus and several longitudinal fibrillae situated in them. These cells had been supposed to be non-cellular substances by previous workers.

3) The epithelial cells of the uterus showed several types of typical grandular structures. The protein coat of ovium is considered to originate from them.

4) Generally the cells consisting female reproductive organ showed polynucleolity.

5) Not only branched parts of the reproductive organ but also about a half length of an unbranched part should be regarded as uterus, the vagina should be only a last half part of the unbranched tube.

6) Judging from the observation of basal composition of the tissues, the female reproductive organ should be divided into two main part; (1) the ovary consisted of a layer of epithelial cells and outer basal membrane and (2) the oviduct, seminal receptacle, uterus and vagina consisted of an inner glandular epithelial layer possessing two nuclei in each cell, middle basal membrane and outer cortical muscle layer. 
7) The relation of oögenesis to the parts of the reproductive organ and its general structure were described.

\section{REFERENCE}

(1) Cason, J. E.: A rapid one-step Mallory-Heidenhain stain for connective tissue. Stain Tech. 25 (4) : 225-226, 1950

(2) Ida Shozo: Finer structure of egg cell of Ascaris. Keio Igaku 10(16): , 1930 (in Japanese)

(3) Izumi Seiichi: Biological studies on ascaris eggs. III. Appearance and decline of nucleic acid, fat and glycogen in consequence of ascaris oögenesis. Jap. Med. J. 5(1) : 45-51, 1952

(4) Lillie, R. D.: An improved acid hemalum formula. Stain Tech. 17(2) : 89, 1942

(5) Murata Shohei: On the distribution of glycogen and fatty substance in development of Ascaris. Nippon Kiseichugakkai Kiji 19: 49-50, 1950

(6) Suzuki Karoku: On glycogen in Ascaris suilla. Keio Igaku 18(11):1193-1198 (in Japanese), 1938

(7) Yamaguchi Ryukei: On the oögenesis of Ascaris. Okayama-Igakkai-Zasshi $64(1): 1-20,1952$ 


\section{EXPLANATION OF THE PLATES}

Pl. 1-1: A-1, Sch-G; primitive ovary showing a layer of epithelial cells and numerous oögonia.

2: A-2, Sch-G; epithelial cells situated separately one another and differentiating axis.

3: A-2, Sch-G; showing intermediate type of the epithelial cells to B-type and "bilobate radical axis".

4: A-2-B-1, Sch-G; 'elongated oöcytes in growth period, intermediate type of the epithelial cells and a cylindrical axis.

5: B-1, Sch-G; B-type epithelial cells with a nucleus including two nucleoli.

6: B-1-B-2, Sch-G; nuclei of oöcytes located in the distal part of cytoplasm.

7: B-2, Sch-MN; showing typical cylindrical axis and nuclei of oöcytes arranged on a same line forming a circle around the central axis.

8: B-2, Sch-MN; alveolar axis showing no differentiation into central or peripheral parts.

9: B-2, RG-Q; lower part than above, showing several types of epithelial cells possessing one to four cytoplasmic processings and tonofiblillae in them.

Pl. 2-10: B-2-B-3, RG-Q; degeneration of axis and cytoplasmic granules in oöcytes.

11: B-3, Sch-MN; fading out of axis.

12: B-3, F-MN; terminal part of ovary showing elongated ellipsoidal oöcytes.

13: C-1, Sch-MN; initial part of oviduct showing appearance of a muscle layer and gibbous epithelial cells.

14: C-1-C-2, F-MN; lower part than above.

15: C-2, RG-Q; seminal receptacle, showing protruced cytoplasm of epithelial cell surrounded by numerous spermatozoa and robust muscle layer.

16: D-1, F-MN; bluish secretory granules stained by MN.

17: D-2, Sch-Q; fibrous endoplasm and hyaline ectoplasm of epithelial cells.

18: D-2, F-Q; same part as above.

Pl. 3-19: D-3, F-MN; showing the process of the secretion.

20: D-3, F-MN; two nuclei in an epithelial cell, numerous spermatozoa localized between epithelial cells, fibrous structure of the epithelial cytoplasm and secretory substance stained red by MN.

21: D-3, F-MN; longitudinal section of the same part as above, showing binucleality of epithelial cells, fibrous cytoplasm and polynucleolity.

22: D-4, F-MN; terminal part of the binary uterus.

23: D-4, F-MN; contractile stage of the same part as above.

24: D-4, Sch-Q; terminal part of the uterus.

25: D-4, Sch-Q; as above.

26: E, F-G; vagina.

27: E, F-G; lower part than above. 

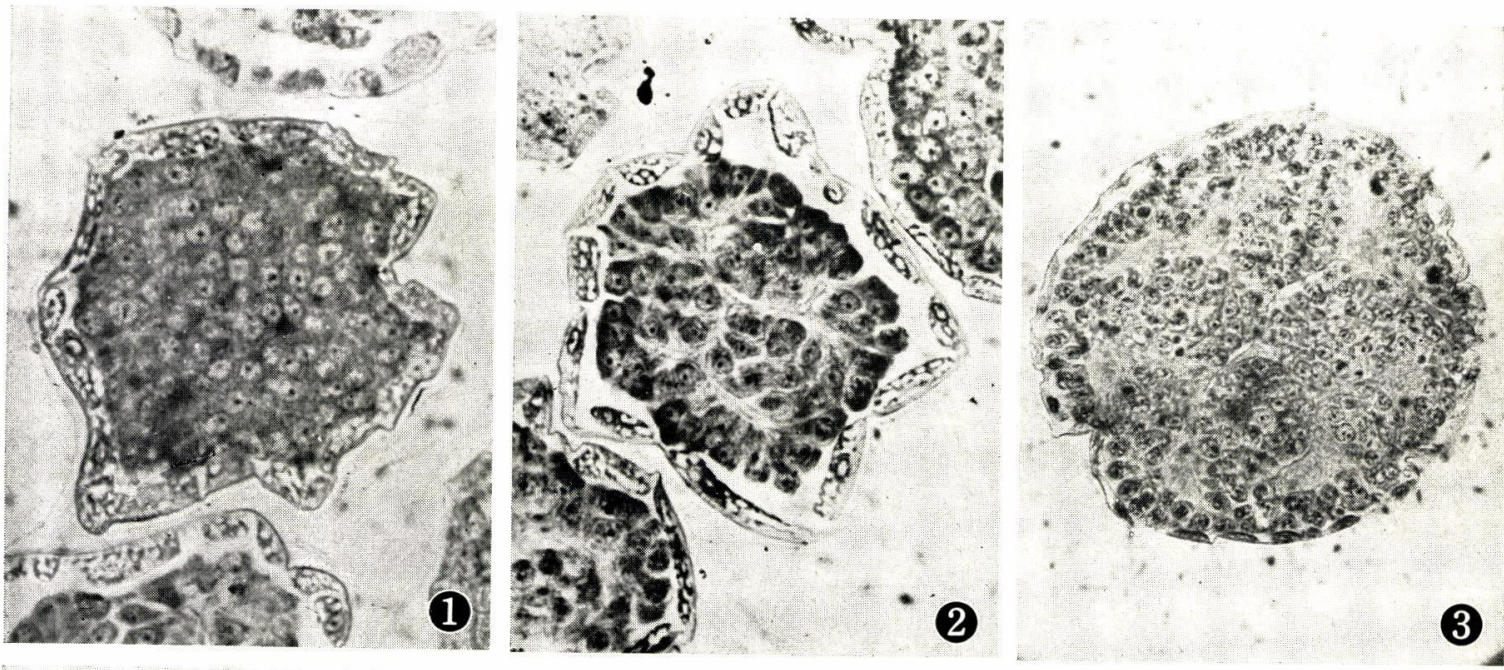

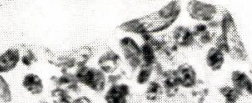

2.

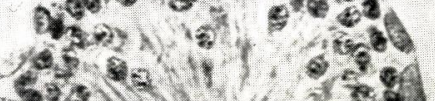

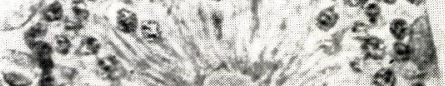

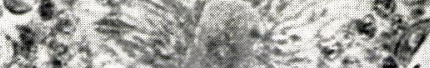

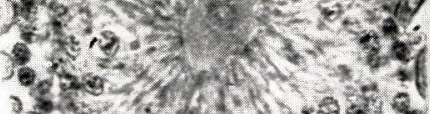

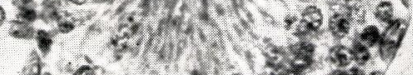
$9.60 ; 0$

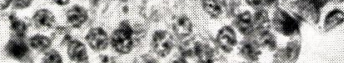
$\left.35 y^{2}\right)^{2}$

4

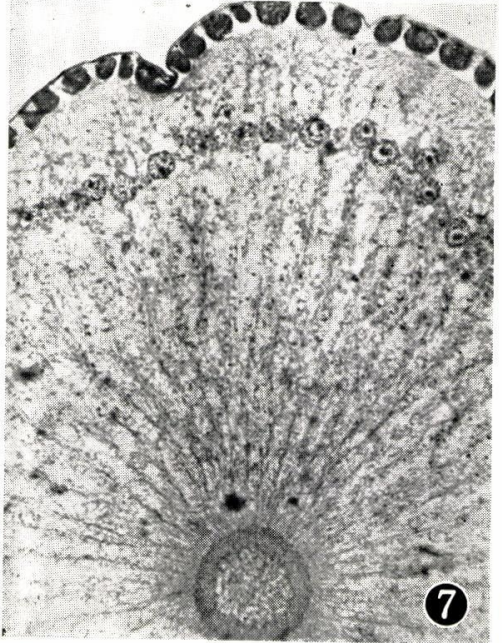

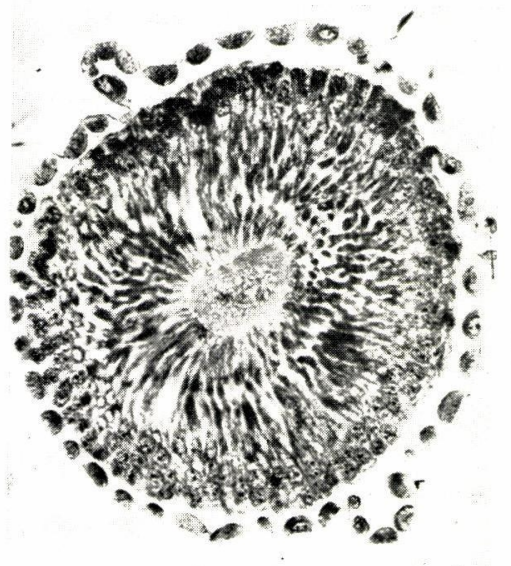

(5)

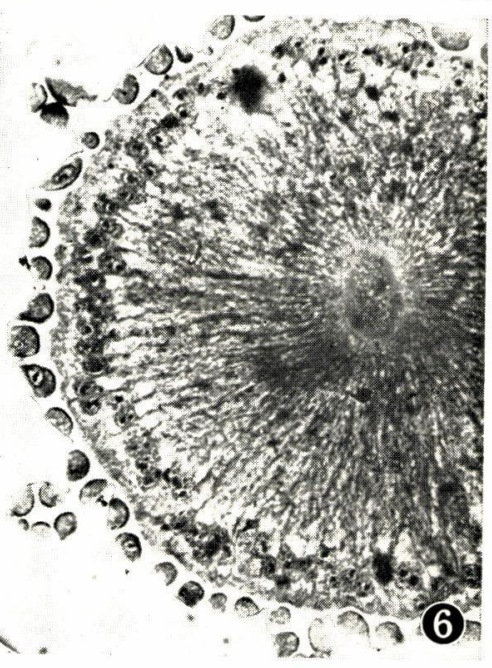

समझ

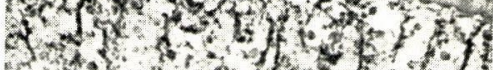

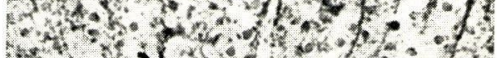

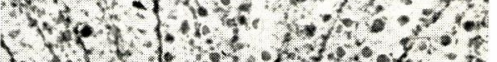
C.

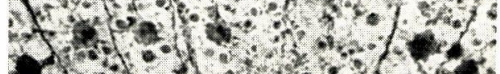

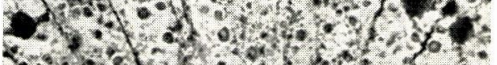

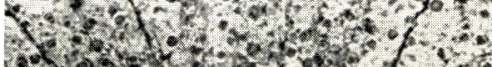

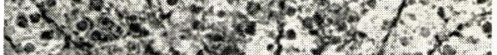

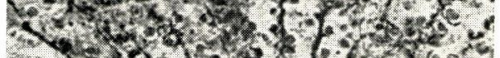

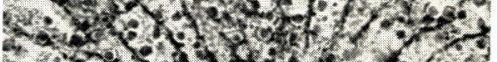

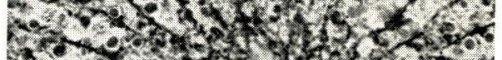
ard 50 mine 


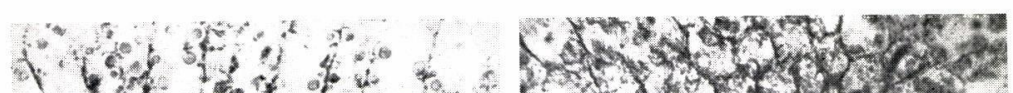

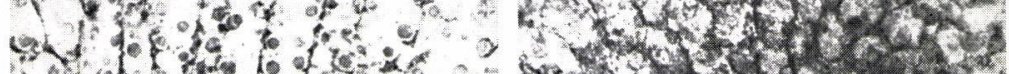

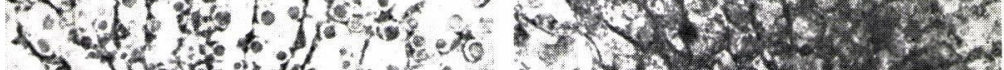

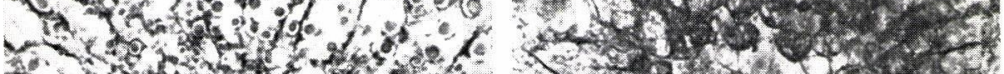

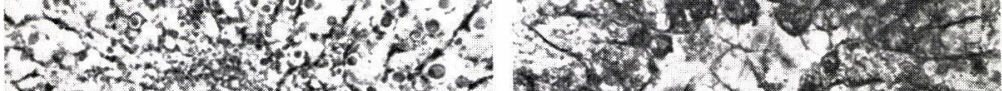

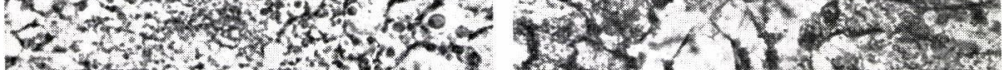

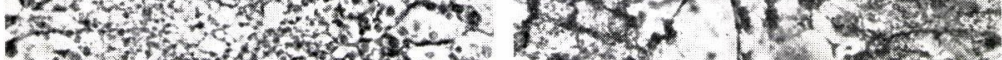

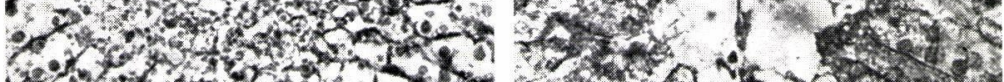

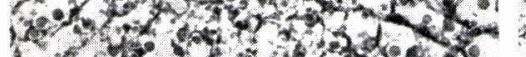

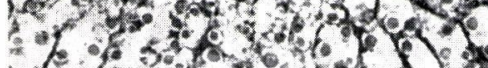

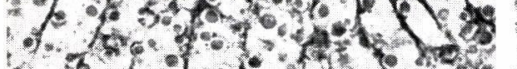

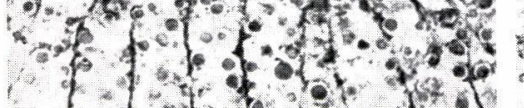

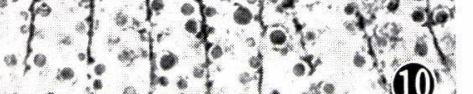

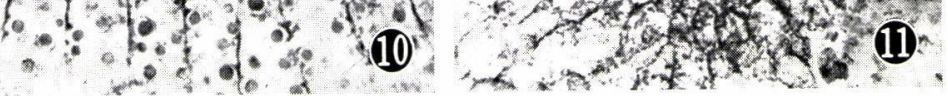
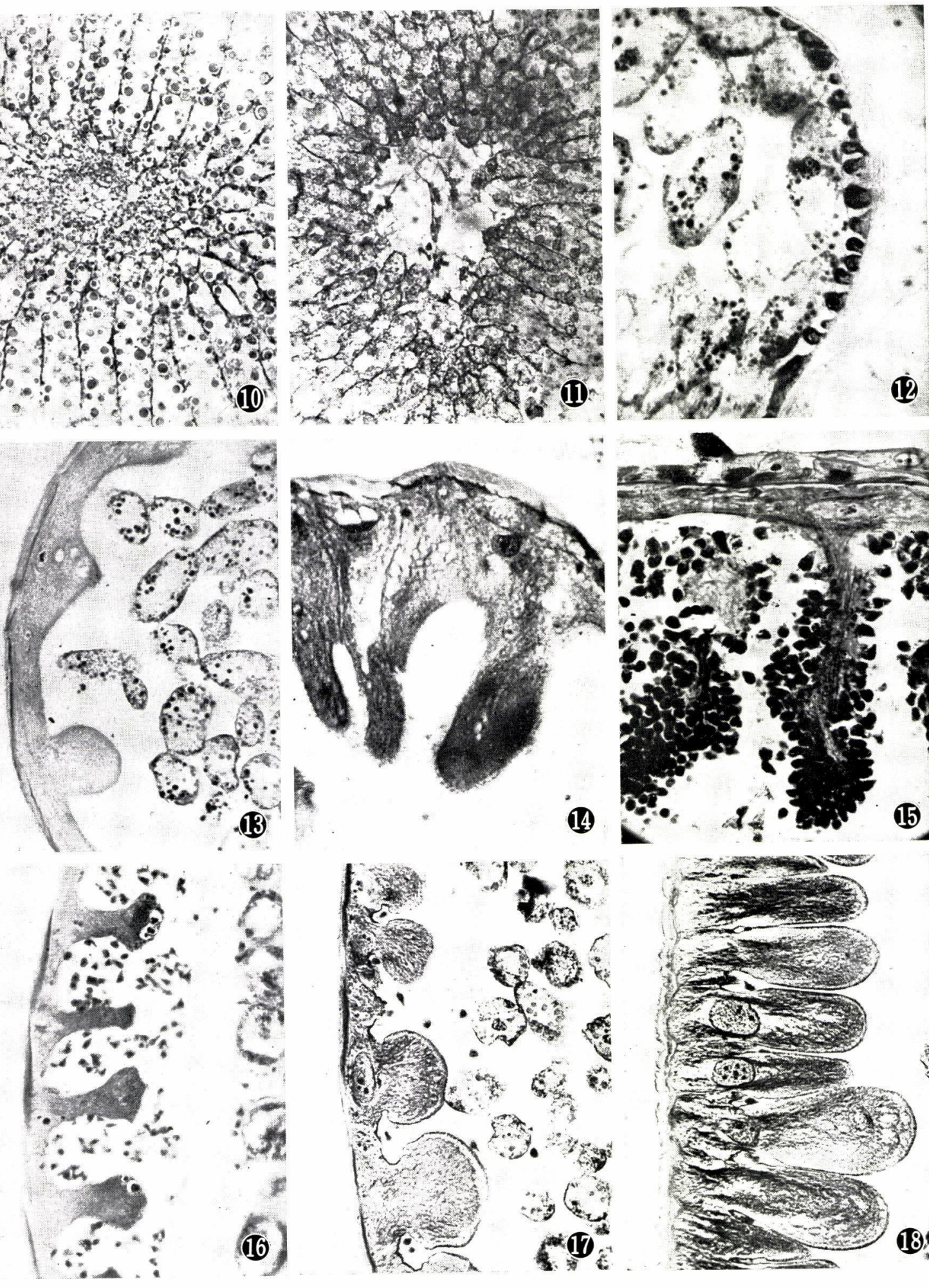
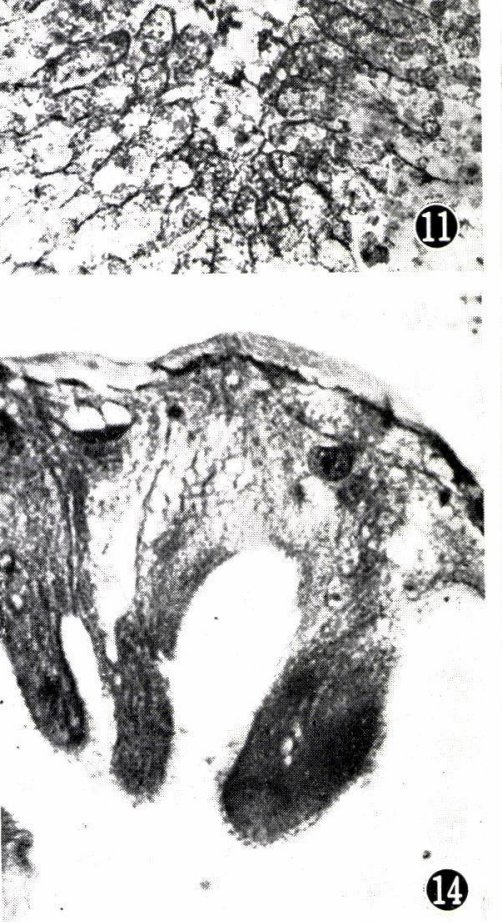

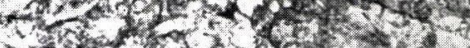

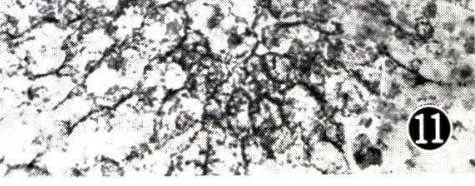

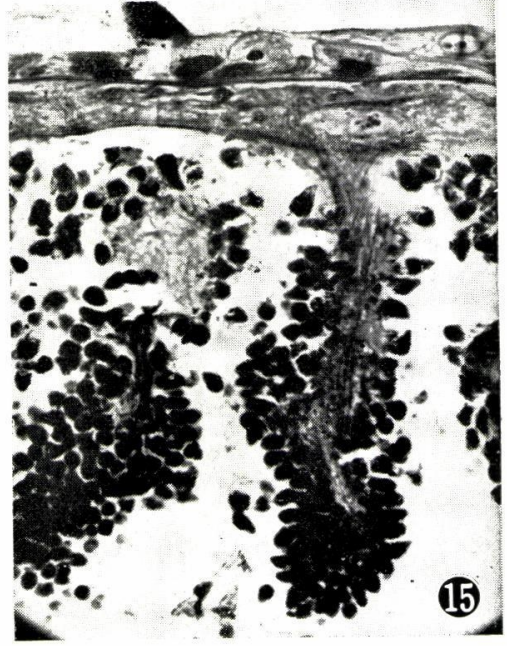

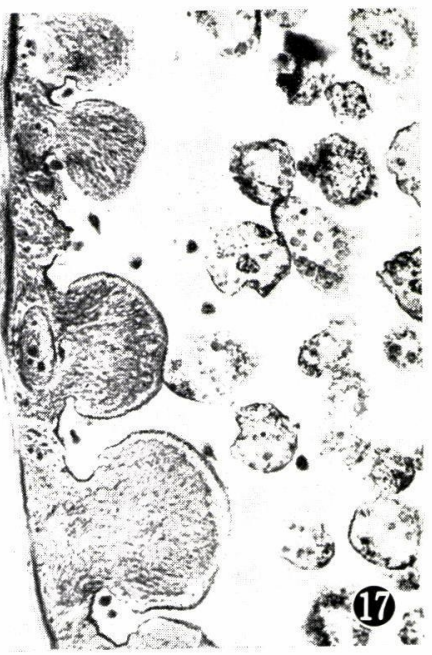

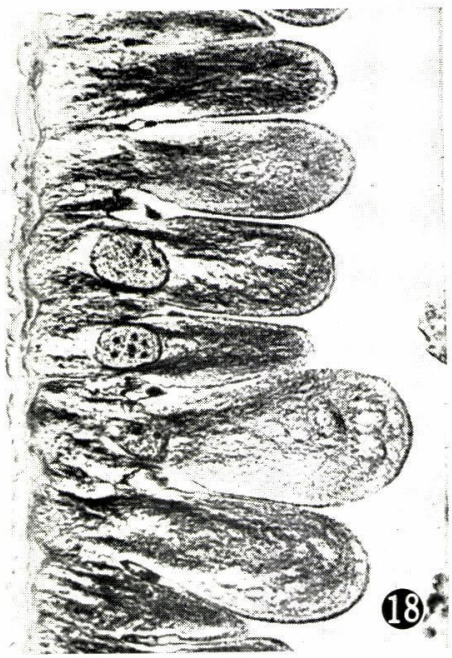




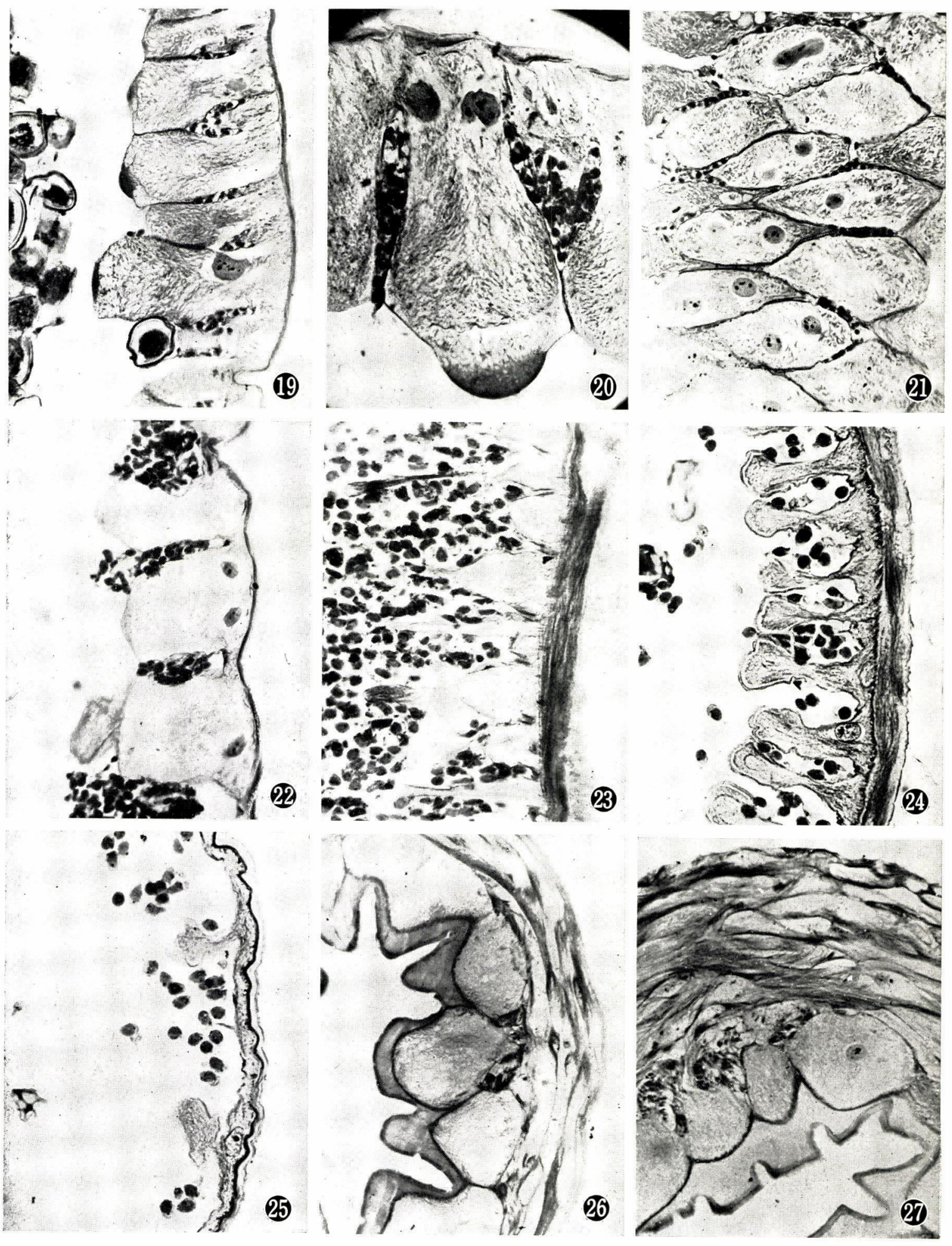

